\title{
Maxillofacial trauma in relation to patients' sobriety - a one-year epidemiological analysis
}

\author{
Anna Gawęda', Mateusz Pisarski' ${ }^{1}$, Jarosław Konopelko' ${ }^{1}$, Krystian Kuźniarz' \\ ${ }^{1}$ University Department of Maxillofacial and Oral Surgery in Lublin \\ Gawęda A, Pisarski M, Konopelko J, Kuźniarz K. Maxillofacial trauma in relation to patients' sobriety - a one-year epidemiological analysis. \\ J Pre-Clin Clin Res. 2014; 8(1): 17-22.
}

\begin{abstract}
Introduction. The maxillofacial skeleton protects the areas particularly susceptible to injuries. Maxillofacial fractures occur when the force of an injury exceeds the biomechanical bone tolerance. Excessive alcohol consumption evokes violence, brutality and assault and other harmful human behaviour. Alcohol abuse seems to be crucial in evoking situations resulting in severe maxillofacial traumas or permanent disability.

Objective. The aim of the study was an epidemiological analysis of patients admitted to hospital to Chair and Clinic of Maxillofacial Surgery in Medical University of Lublin in 2011 due to facial traumas. This study discusses the association between alcohol consumption and maxillofacial trauma.

Materials and method. The research group constituted 226 patients admitted to hospital due to facial trauma in 2011 . The following factors were considered in the study: patients' age, cause of trauma, place of residence, and alcohol consumption prior to the trauma.

Conclusions. It was observed that $53 \%$ of the patients underwent maxillofacial trauma while under the influence of alcohol. Its consumption was significant in the analysis of gender, age, cause of trauma, and the place of residence of patients with maxillofacial trauma examined within one year.
\end{abstract}

\section{Key words}

facial trauma, epidemiology, alcohol consumption

\section{INTRODUCTION}

The cranium plays a significant role in the human body as it protects the nervous, visual, respiratory, alimentary and stomatognathic systems, all of which are indispensable for the proper functioning of the whole organism. Cranial injuries may result in permanent disability and life threatening conditions.

The maxillofacial structure protects the areas particularly susceptible to injuries. These are the most central and lateral prominences of the facial skeleton. They absorb the force aimed at this particular body area functioning as 'bumpers'. Facial 'bumpers' include zygomatic, nose, incisor, and mental 'bumpers" [1].

Two mechanisms, direct and indirect, result in facial fractures. They can occur separately or together. Fractures in the direct mechanism occur when excessive force is not compensated by the facial tissues. Whereas fractures in the indirect mechanism result from straightening the Sicher pillar arches at the point of the greatest curves $[1,2]$.

A bone biomechanical tolerance depends on such factors as impact, duration, application and direction. The force duration has a considerable influence on fracture occurrence. Force duration exceeding 4 milliseconds reduces the zygomatic bone tolerance to fracture by $150-250 \%$. The greater the force, the greater the susceptibility to fracture, $1,000 \mathrm{lbs}$ factor causes zygomatic bone fracture within 3 milliseconds [3]. Bones present the highest tolerance when subject to axial forces and the lowest tolerance when subject to shear forces. Transverse forces are classified in-between [4].

Address for correspondence: Anna Gawęda, ul. Poznańska, 20-731 Lublin, Poland e-mail: agaweda5@wp.pl

Received: 26 November 2013; accepted: 24 April 2014
Comparison of facial skeleton tolerance shows differences in the impact application and its pressure on the bones which constitute the facial skeleton. The lower the value of these elements, the higher the risk of a fracture. The nose bone has the least endurance, its tolerance of applied force and pressure is $342-450 \mathrm{~N}$ and $0.13-0.34 \mathrm{~N} \mathrm{~mm}^{-2}$. The most enduring facial skeleton bone is the frontal bone whose structure can resist the impact of 6,494 $\mathrm{N}$ and a pressure equal to or higher than $7.58 \mathrm{~N} \mathrm{~mm}^{-2}$. Critical values for the zygomatic bone and arch, mandible and maxilla are presented in Table [5].

On post-mortem examination, the head of the human has been assumed to weigh approximately $15 \mathrm{lbs}$. It moves with the acceleration of $80 \mathrm{G}$ in a road traffic accident when the speed of the vehicle is $50 \mathrm{~km} / \mathrm{h}$. Thus, it has been estimated that the force of the blow equals $1,200 \mathrm{lbs}$ which may result in fracture of the nose, zygoma, mandible and the front part of the frontal sinus. The fracture of the mandible shaft and maxilla shaft requires the force of a blow of at least $1,500 \mathrm{lbs}$ and a fracture of the frontal bone requires 3,000lbs [6].

The mandible being the lower part of the facial skeleton is the most susceptible to fractures. Despite its high endurance to bending and stretching its anatomical position - protruding and lack of protection from other bones - predisposes it to common injuries $[1,2]$.

Assaults, road traffic accidents (both car and motorcycle accidents) domestic violence, falls and accidents at work were the most common causes of facial traumas $[7,8,9,10]$ in the Lublin Region in 2011. 7.28\% of the surveyed patients admitted to alcohol abuse, which makes it the eighth value in the country [11] and the third highest risk factor for morbidity [9]. Alcohol consumption results in perception impairment which increases the risk of accidents and injuries of various parts of the body. Alcohol abuse leads to aggression, violence, and tendency to fights and other hazardous behaviours. 
Table 1. Summary of facial bone tolerances

\begin{tabular}{|c|c|c|c|c|}
\hline Bone & $\begin{array}{l}\text { Force } \\
\text { tolerance } \\
(\mathrm{N})\end{array}$ & Reference & $\begin{array}{l}\text { Pressure } \\
\text { tolerance } \\
\left(\mathrm{N} \cdot \mathrm{mm}^{-2}\right)\end{array}$ & Reference \\
\hline Zygoma & $489-2401$ & $\begin{array}{l}\text { Nyquist et al. (1986), } \\
\text { Hodgson (1967), } \\
\text { Gadd et al. (1988), } \\
\text { Allsop et al. (1988) }\end{array}$ & $1.38-4.17$ & $\begin{array}{l}\text { Nahum (1976), Gadd } \\
\text { et al. (1968) }\end{array}$ \\
\hline $\begin{array}{l}\text { Zygomatic } \\
\text { arch }\end{array}$ & $890-1779$ & $\begin{array}{l}\text { Schneider and } \\
\text { Nahum (1974), } \\
\text { Nahum (1976) }\end{array}$ & $1.38-2.76$ & $\begin{array}{l}\text { Nahum (1976), } \\
\text { Hodgson (1967) }\end{array}$ \\
\hline Mandible & $685-1779$ & $\begin{array}{l}\text { Nyquist et al. (1986), } \\
\text { Gadd et al. (1968) }\end{array}$ & $2.76-6.20$ & $\begin{array}{l}\text { Schneider and } \\
\text { Nahum (1974) }\end{array}$ \\
\hline Maxilla & $668-1801$ & $\begin{array}{l}\text { Allsop et al. (1988), } \\
\text { Hodgson (1967) }\end{array}$ & $1.03-2.07$ & $\begin{array}{l}\text { Nahum (1976), } \\
\text { Schneider and } \\
\text { Nahum (1974) }\end{array}$ \\
\hline Frontal & $1000-6494$ & $\begin{array}{l}\text { Nyquist at al. (1986), } \\
\text { Allsop et al. (1988), } \\
\text { Gadd et al. (1968) }\end{array}$ & $\geq 7.58$ & Gadd et al. (1968) \\
\hline Nose & $342-450$ & $\begin{array}{l}\text { Nyquist et al. (1986), } \\
\text { Swearingen (1965) }\end{array}$ & $0.13-0.34$ & Nahum (1976) \\
\hline
\end{tabular}

Two billion people worldwide are estimated to consume alcohol, 76 million of them are diagnosed with alcohol use disorder (World Health Organization, 2004) [9].

Studies have consistently shown the face to be a commonly targeted region in alcohol-related violence. In some countries, alcohol abuse has continued to be a major social problem playing a crucial role in dangerous situations, resulting in severe maxillofacial traumas, body injuries, permanent disability or death $[7,12,13,14]$.

Objective. The aim of the study was an epidemiologic analysis of maxillofacial trauma patients admitted to hospital, to the Chair and Clinic of Maxillofacial Surgery of Medical University in Lublin, Poland, in 2011. The study analysed such factors as patients' gender, cause of the trauma, age and place of residence. The study focuses on the association between alcohol consumption and maxillofacial trauma.

\section{MATERIALS AND METHOD}

The analysis was conducted on a group of 226 facial injury patients examined at the Chair and Department of Maxillofacial Surgery of the Medical University of Lublin in 2011. Post-traumatic examination was carried out with clinical examination and common X-ray examination, in some doubtful cases computer tomography was performed.

The studied group comprised patients aged 18-80 (mean value 31 years old). Males constituted $97 \%$ and females $7 \%$ (Fig. 1). 53\% of the patients were under the influence of alcohol on admission or at the moment of injury (Fig. 2). On examination, the patient informed about the state of sobriety at the moment of injury. Blood tests were not routinely conducted due to some legal constraints, therefore clinical assessment and the patients' honesty were relied on. The patients were treated with orthopaedic methods and stable surgical osteosynthesis. The study compared the frequency of injuries, patients' gender, causes and circumstances of the injuries, the place of residence of the sober and drunk patients using the Wilcoxon signed-rank test. Pertinence level $\mathrm{p}<0.05$ indicating the presence of statistically significant

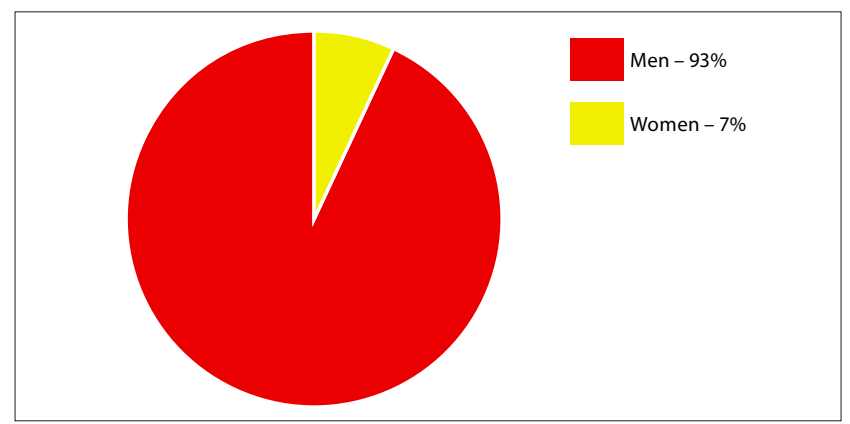

Figure 1. The division of patients by gender

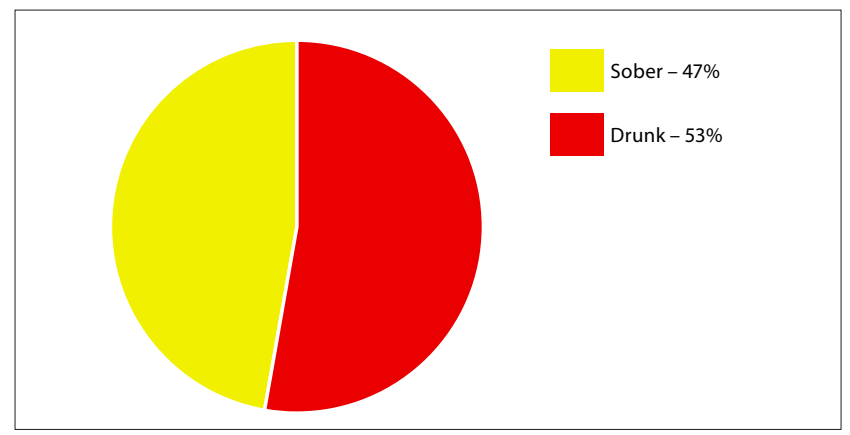

Figure 2. Division of patients due to state of sobriety

differences or dependencies was adopted. The results were subjected to statistical analysis using a Statistica 6.0 computer programme.

\section{RESULTS}

Patients under the influence of alcohol were diagnosed with mandibular fractures (62.8\%), zygomatico-maxillo-orbital fractures (20.1\%), nasal fractures (3.8\%), maxillary fractures (3.1\%), orbital fractures $(8.7 \%)$, zygomatic arch fractures (1.5\%). Sober patients were diagnosed with mandibular fractures $(62.7 \%)$, zygomatico-maxillo-orbital fractures (11.4\%), nasal fractures (6.2\%), maxillary fractures (7.9\%), orbital fractures (6.2\%), zygomatic arch fractures (2.6\%) (Tab. 2).

Table 2. Comparison of sobriety and fracture location among patients

\begin{tabular}{lccc}
\hline & Sober patients & Drunk patients & Total \\
\hline Mandibular fractures & $65.7 \%$ & $62.8 \%$ & $64.2 \%$ \\
\hline Fractures zygomatico-maxillo-orbital & $11.4 \%$ & $20.1 \%$ & $16 \%$ \\
\hline Nasal fractures & $6.2 \%$ & $3.8 \%$ & $4.9 \%$ \\
\hline Jaw fractures & $7.9 \%$ & $3.1 \%$ & $5.4 \%$ \\
\hline Orbital fractures & $6.2 \%$ & $8.7 \%$ & $7.4 \%$ \\
\hline Fractures of the zygomatic arch & $2.6 \%$ & $1.5 \%$ & $2.1 \%$ \\
\hline
\end{tabular}

More males under the influence of alcohol (51\%) than females (2\%) were admitted to hospital due to facial traumas. Among the sober patients, $42 \%$ were males and 5\% females (Fig. 3).

The patients were divided into five groups according to the causes of trauma, namely: assault, road traffic accident, sport, fall and work. Assault was the main cause of all traumas among $44.2 \%$ of the patients who were under the influence of alcohol, and $22.1 \%$ sober patients. The revealed differences 


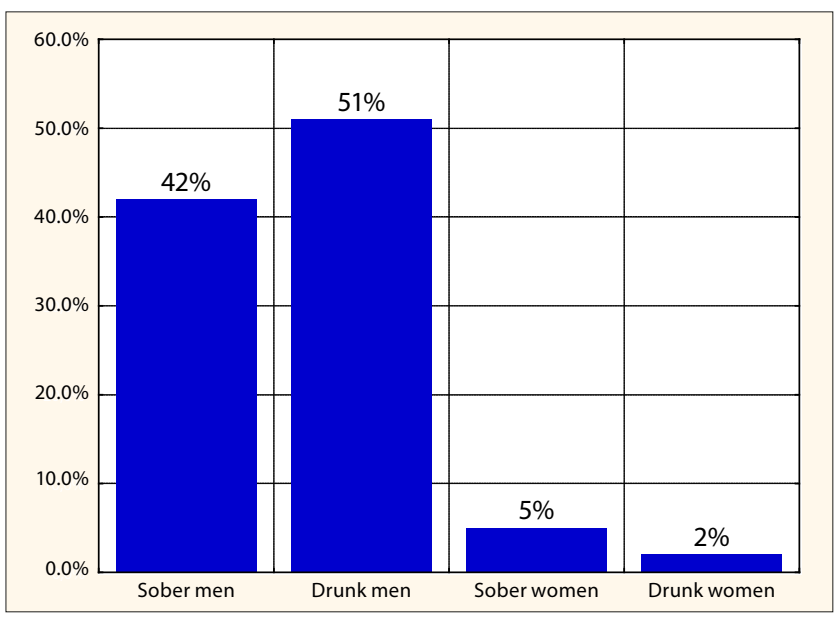

Figure 3. Division of patients by gender and state of sobriety

were statistically significant $(\mathrm{p}=0.000005) .5 .8 \%$ of patient who suffered facial trauma in a road traffic accident were under the influence of alcohol, whereas $8.4 \%$ were sober. All the patients who incurred facial trauma while performing sport were sober and constituted 4\%. Statistical analysis showed a significant relation between drunk and sober patients engaged in sport $(\mathrm{p}=0.024) .10 .7 \%$ of facial trauma patients were admitted to hospital after a fall, and only $2.7 \%$ were under the influence of alcohol. The remaining $8 \%$ were sober. $4.8 \%$ of patients who incurred a facial trauma at work were drunk and $4.4 \%$ were under the influence of alcohol, $0.4 \%$ patients drank alcohol prior to an accident. The revealed differences were statistically significant $(p=0.015)$ (Tab. 3).

Table 3. Cause of injury related to state of sobriety

\begin{tabular}{lrrrrrl}
\hline \multirow{2}{*}{ Cause of injury } & \multicolumn{2}{c}{ Drunk } & \multicolumn{2}{c}{ Sober } & \multirow{2}{*}{ Statistical analysis "p" } \\
\cline { 2 - 5 } & $\mathrm{n}$ & \multicolumn{2}{c}{$\%$} & $\mathrm{n}$ & $\%$ & \\
\hline Assault & 100 & $44.2 \%$ & 50 & $22.1 \%$ & 0.000002 \\
\hline Accident & 13 & $5.8 \%$ & 19 & $8.4 \%$ & - \\
\hline Sport & 0 & $0.0 \%$ & 9 & $4.0 \%$ & 0.045 \\
\hline Fall & 6 & $2.7 \%$ & 18 & $8.0 \%$ & 0.024 \\
\hline Working & 1 & $0.4 \%$ & 10 & $4.4 \%$ & 0.015 \\
\hline
\end{tabular}

Next, the correlation between the cause of trauma and age of the patients was investigated. The patients were divided into four age groups: under 18-years-old, 19-40, 41-60, and over 61-years-old. Analysis among the oldest group was not statistically significant due to the insufficient number of patients. Assaults were the most common cause among patients aged $19-40$, where $48.7 \%$ of them were under the influence of alcohol and 21.3\% were sober. Differences were considered statistically significant $(\mathrm{p}=0.000) .12 \%$ of minors were admitted to hospital due to the same cause and 5.3\% of the patients were drunk whereas $6.7 \%$ were sober. The differences achieved statistical significance $(\mathrm{p}=0.013)$. Among the patients aged $41-60,1.3 \%$ of them were admitted to hospital after an assault, in which $11.3 \%$ of patients were under the influence of alcohol and $4.7 \%$ were sober. Statistical comparison revealed statistical significance $(\mathrm{p}=0.000008)$. $1.3 \%$ of patients older than 60 were under the influence of alcohol. (Tab. 4).

Having analysed road traffic accidents, the most numerous group of casualties constituted patients aged 19-40 years old.
Table 4. Assault as a cause of injury in different age groups

\begin{tabular}{lrrrrr}
\hline \multirow{2}{*}{ Age } & \multicolumn{2}{c}{ Drunk } & \multicolumn{2}{c}{ Sober } & \multirow{2}{*}{ Statistical analysis "p" } \\
\cline { 2 - 5 } & $\mathrm{n}$ & $\%$ & $\mathrm{n}$ & $\%$ & \\
\hline$<18$ & 8 & $5.3 \%$ & 10 & $6.7 \%$ & 0.013 \\
\hline $19-40$ & 73 & $48.7 \%$ & 32 & $21.3 \%$ & 0.0000 \\
\hline $41-60$ & 17 & $11.3 \%$ & 7 & $4.7 \%$ & 0.000008 \\
\hline $61<$ & 2 & $1.3 \%$ & 1 & $0.6 \%$ & \\
\hline
\end{tabular}

$24.2 \%$ out of $66.6 \%$ patients were under the influence of alcohol and $42.2 \%$ were sober. Only $6.1 \%$ of patients constituted minors and all of them were sober. Among 41-60-year-old patients, $24.3 \%$ were involved in road traffic accidents, and $15.2 \%$ of them had drunk alcohol prior to the accident. Only one person belonging to the oldest age group of over 60 was under the influence of alcohol and constituted $3 \%$ of the researched group. (Fig. 4).

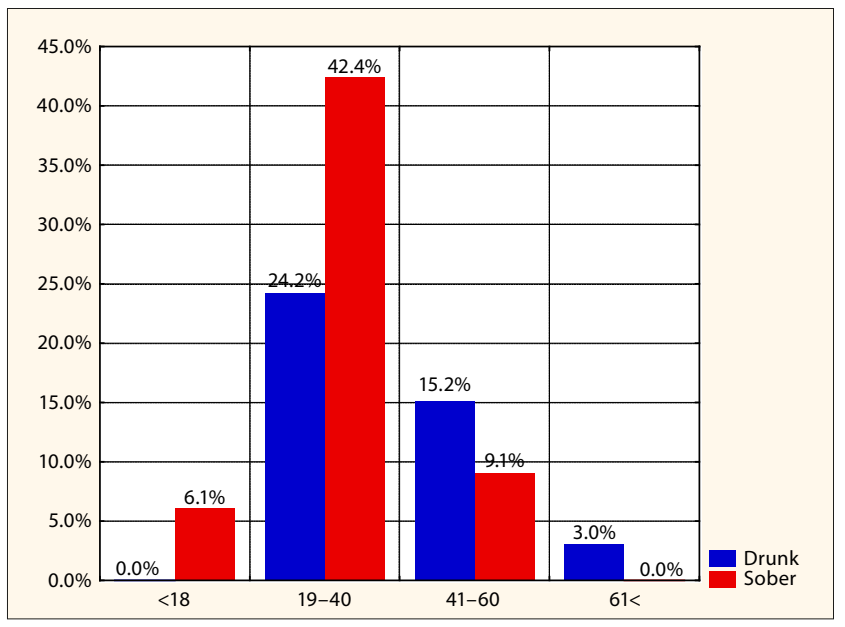

Figure 4. Accident as a cause of injury in different age groups

$63.6 \%$ of patients aged $41-60$ suffered from accidents at work and $9.1 \%$ of them were drunk. $18.2 \%$ patients aged 19-40 years old were sober. Under-age patients and those older than 60 formed $9.1 \%$ of these treated in each age group, and all of them were sober. (Fig. 5).

The most numerous examples of a facial trauma as a result of a fall were patients aged $19-40(60.8 \%)$ and $21.7 \%$ of them

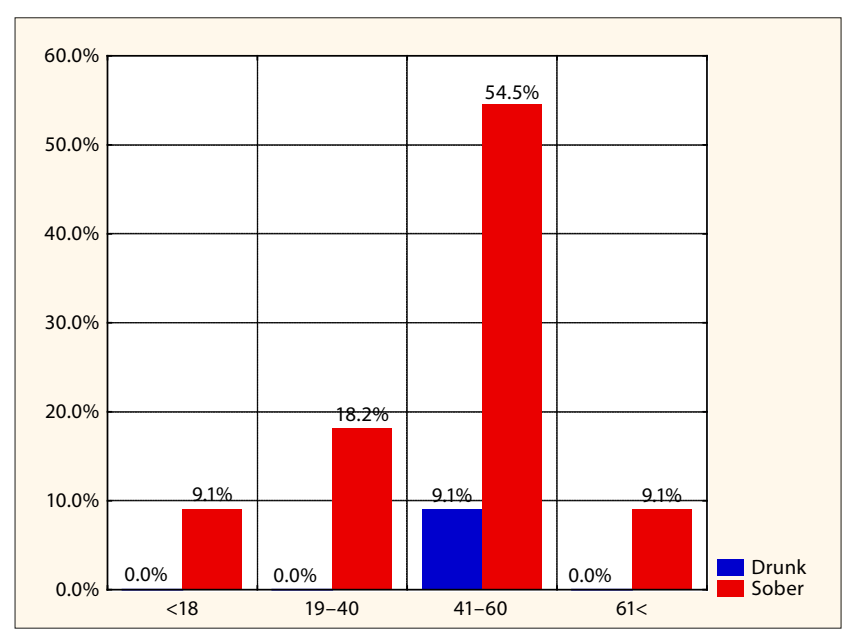

Figure 5. Working as a cause of injury in different age groups 
were under the influence of alcohol. $17.4 \%$ of patients under the age of 18 and $21.7 \%$ of patients aged $41-60$ were admitted to hospital. None of them were under the influence of alcohol. No patients older than 60 were reported. The analysis of this facial trauma cause was not considered statistically significant. (Fig. 6).

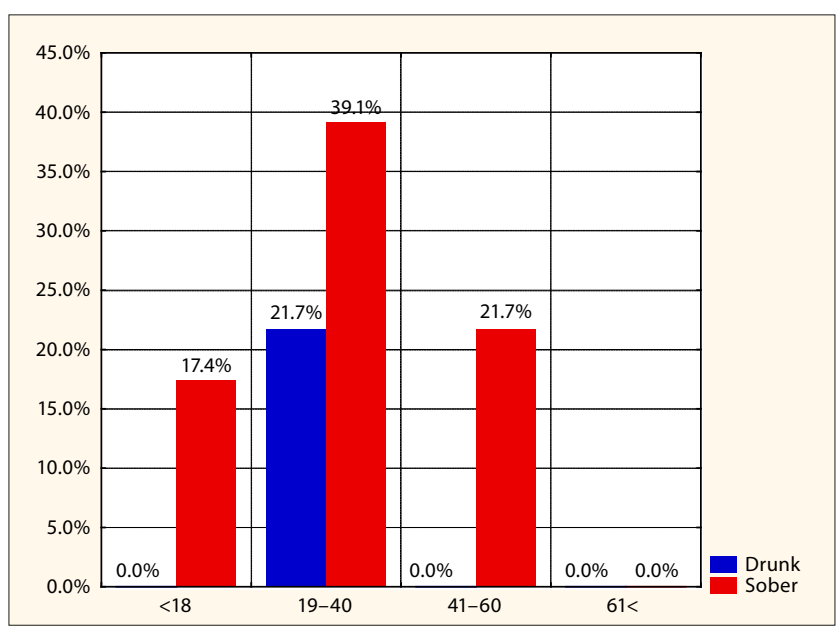

Figure 6. Fall as a cause of injury in different age groups

$3.9 \%$ of patients incurred facial injuries while engaged in sport (33.3\%) and who were under-age patients, 55.5\% patients aged $19-40$, and $11.1 \%$ of patients aged $41-60$. No patients older than 60 years of age were reported. None of the patients were under the influence of alcohol (Fig. 7).

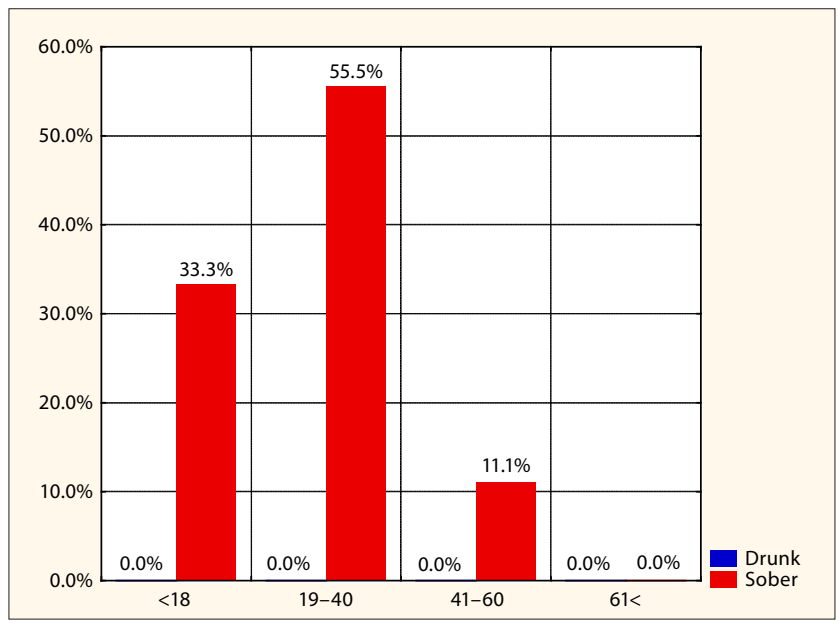

Figure 7. Sport as a cause of injury in different age groups

The correlation between the place of residence and the cause of the facial trauma showed that more injuries were reported in the urban areas (54\%) compared to $46 \%$ of patients residing in the rural areas (Fig. 8).

In urban areas, assault was the main cause of facial trauma in which $28.3 \%$ of patients were under the influence of alcohol at the moment of the injury, and $11.1 \%$ were sober. The revealed differences were statistically significant $(\mathrm{p}=0.007)$. $3.6 \%$ of patients were traffic accident casualties, $2.7 \%$ of whom were drunk. Alcohol was not detected in $0.9 \%$ of the patients. $2.2 \%$ of patients suffered from facial trauma while engaged in sport and all of them were sober. A fall was the second most common cause of facial trauma in urban areas. Among $6.6 \%$ of the patients, $2.2 \%$ were drunk and $4.4 \%$ were sober.

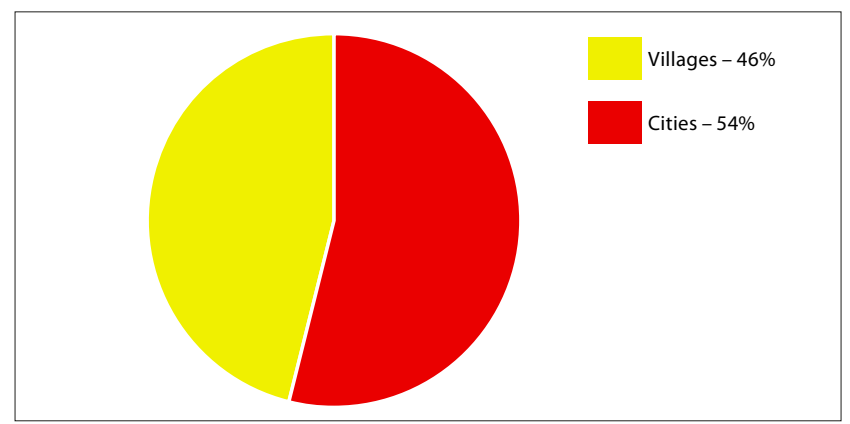

Figure 8. Place of residence of patients

All the patients who had facial traumas at work were sober and constituted $2.2 \%$. In the case of road traffic accidents, engaged in sport, suffering from a fall and working, there were no statistically significant differences between the cause of trauma and sobriety (Tab. 5).

Table 5. Injuries occurring in urban areas

\begin{tabular}{lccccc}
\hline \multirow{2}{*}{ Cause of the injury } & \multicolumn{2}{c}{ Drunk } & \multicolumn{2}{c}{ Sober } & \multirow{2}{*}{ Statistical analysis "p" } \\
\cline { 2 - 5 } & $\mathrm{n}$ & $\%$ & $\mathrm{n}$ & $\%$ & \\
\hline Assault & 64 & $28.3 \%$ & 25 & $11.1 \%$ & 0.007 \\
\hline Accident & 6 & $2.7 \%$ & 2 & $0.9 \%$ & - \\
\hline Sport & 0 & $0.0 \%$ & 5 & $2.2 \%$ & - \\
\hline Fall & 5 & $2.2 \%$ & 10 & $4.4 \%$ & - \\
\hline Working & 0 & $0.0 \%$ & 5 & $2.2 \%$ & - \\
\hline
\end{tabular}

The dominant cause of facial traumas in the rural areas was also assault, where $15.9 \%$ of patients were under the influence of alcohol and $11.1 \%$ were sober. Statistical analysis showed a significant relationship ( $\mathrm{p}=0.002)$. Road traffic accidents were more common in rural areas and $3.1 \%$ of casualties admitted alcohol consumption prior to the accident, while $7.5 \%$ of the patients were sober. All the $1.8 \%$ of patients engaged in sport were not under the influence of alcohol. 3.9\% of patients had incurred facial traumas while falling badly; $0.4 \%$ of them were drunk and $3.5 \%$ were sober. The revealed differences were considered statistically significant ( $\mathrm{p}=0.045)$. Only $0.4 \%$ of patients who suffered from facial traumas at work were drunk and $2.2 \%$ were sober. In the case of road traffic accidents, engaged in sport, and accidents at work, no statistically significant differences between the cause of the trauma and sobriety were revealed (Tab. 6).

Table 6. Injuries occurring in rural areas

\begin{tabular}{lccccc}
\hline Cause of the injury & Drunk & \multicolumn{3}{c}{ Sober } & \multicolumn{2}{c}{ Statistical analysis "p" } \\
\hline Assault & $\mathrm{n}$ & $\%$ & $\mathrm{n}$ & $\%$ & \\
\hline Accident & 36 & $15.9 \%$ & 25 & $11.1 \%$ & 0.002 \\
\hline Sport & 7 & $3.1 \%$ & 17 & $7.5 \%$ & - \\
\hline Fall & 0 & $0.0 \%$ & 4 & $1.8 \%$ & - \\
\hline Working & 1 & $0.4 \%$ & 8 & $3.5 \%$ & 0.045 \\
\hline
\end{tabular}




\section{DISCUSSION}

The presented study shows the significant role of alcohol consumption in the occurrence of facial traumas, and confirmed data obtained by other authors. According to Bali [15], as many as $38.3 \%$ of the group of 740 patients incurring facial trauma in road traffic accidents were under the influence of alcohol. Similarly, Shekar [16], in the course of five-year research, found that $58 \%$ of casualties were drunk. Both authors pointed out that the most common means of transport was a motorcycle. Having examined a group of 6,114 patients, Hutchinson [...] revealed that $40 \%$ of all injuries were caused by a bad fall and $11 \%$ of the patients were under the influence of alcohol; $24 \%$ of traumas were the result of violence and alcohol was found in 55\% of the cases. In 5\% of road accidents and $15 \%$ of casualties the patients had drunk alcohol prior to the accident. The results of the presented study show that $5.8 \%$ of drunk patients and $8.4 \%$ who were sober were involved in road traffic accidents, while assault was the second most common cause of the facial trauma patients admission to hospital. Findings from New Zealand suggest that their greater exposure to alcohol led to an increase in the number of facial fractures among young adults [9]. Young patients treated in the Chair and Department of Maxillofacial Surgery of Medical University in Lublin had not consumed alcohol prior to road traffic accidents, bad falls, or while engaged in sport, and were mostly sober during assaults. Young males were more commonly subjected to maxillofacial trauma as a result of interpersonal violence [18].

O'Meara et al. $[7,19]$ conducted two studies: the first proved that 83 out of 252 patients suffered mandibular fracture and $91 \%$ of 54 assaulted patients were under the influence of alcohol; in the second study, 105 patients out of 202 examined were maxillofacial trauma patients - 105 were victims of assault and $87 \%$ were drunk. In both studies, the authors unanimously claimed that alcohol affects the severity of fractures which lead to the need for surgical treatment. The current research proves that violence was the main cause of assaults under the influence of alcohol. $44.2 \%$ of drunk patients were subject to facial fractures compared to $22.1 \%$ of sober patients.

Elledge [12] attempted to discern the influence of the environment and place of residence on injuries incurred under the influence of alcohol. Research was conducted in two separate centres, namely, Selly Oak Hospital in Birmingham, UK, and Westmead Hospital in Sydney, Australia. In the former hospital, $30.77 \%$ cases of trauma were reported under the influence of alcohol, whereas in the latter, $34.78 \%$ cases were reported. This relationship has not been confirmed in the research. Assault under the influence of alcohol was one of the major causes of trauma in the presented research regardless of the patients place of residence. A significant difference was that drunk patients dominated in the urban areas $-28.3 \%$, compared to rural areas $-15.9 \%$. Another relationship was observed in the analysis of road accidents, where the majority of rural patients (3.1\%) were under the influence of alcohol. According to research conducted by Laverick [13], the predominant cause of traumas was interpersonal violence, where $78 \%$ of cases were caused by alcohol abuse.

Research conducted by Zix in Switzerland [20], proved that among 420 facial trauma patients, $28 \%$ of the cases resulted from road accidents and $21 \%$ from performing sport. $13 \%$ of patients were under the influence of alcohol or narcotics on admission to hospital. According to Lee [21], 49\% out of 2581 patients were drunk at the moment of fracture, and males constituted $88 \%$. $78 \%$ of fractures connected with alcohol abuse were caused by assault and $13 \%$ by road traffic accidents. Lee conducted a broad research, comparing two 5.5-year periods [22]. During the first period, 624 cases of fractures as a result of alcohol consumption were noted, and in the second study, 640 cases were noted. This constituted $73 \%$ and $18 \%$ in the first period and $82 \%$ and $8 \%$ in the second. Van Beek [...] carried out some long-term research in Nijmegen in the Netherlands analysing cases of facial traumas from 1960 to 1987. The research showed that road traffic accidents were the main cause of injuries with a systematically rising number of causes such as assaults and sport, with a $3 \%-12 \%$ increase in alcohol consumption reported. Oikarinen [24] examined the frequency of mandibular fractures related to alcohol abuse in northern Finland in the 1980s. He observed that as many as $49 \%$ of males and $29 \%$ of females were drunk at the time of injury.

According to the presented research, $53 \%$ of patients were under the influence of alcohol at the time of injury, and young male adults were dominant in the group of assault or road traffic accident casualties.

The '24-Hour Alcohol Licensing Law' was introduced in England and Wales on 24 November 2005 which permitted the sale alcohol in gastronomic outlets around the clock. Previously, they could sell alcohol only until 23:00. ElMaaytah [25] compared the number of injuries related to alcohol consumption that occurred prior to and after bringing in the law. The research was conducted during two 6-month periods at University College Hospital in London. During the first six months of the research, 1,102 intoxicated patients with maxillofacial trauma were admitted to the hospital, whereas during the second period, 730 patients were admitted. The new law did not increase but decreased the frequency of traumas related to alcohol abuse.

Chen [14] attempted to show a relationship between alcohol consumption and injury location in road traffic accidents. Among 381 patients admitted to hospital, 21\% were under the influence of alcohol at the time of the accident. The range of traumas was divided into the following areas: head, face, chest, abdomen and the limbs. The frequency of trauma occurrence in those areas among drunk patients was 39\%, $56 \%, 13 \%, 15 \%$ and $55 \%$, respectively, and for sober patients - 26\%, 32\%, 15\%, $12 \%$ and $63 \%$, respectively. The author observed that alcohol consumption affected the frequency of head and face traumas, which is not observed in the case of other parts of the body. In the presented study, the drunk patients were more frequently subjected to zygomaticomaxillo-orbital fractures (20.1\%) and orbital fractures (8.7\%), which could result in surgical problems and difficulties in regaining proper bodily functions.

The research confirmed the effect of alcohol consumption on the occurrence of maxillofacial traumas, which remains a problem not only in the Lublin Region, but also constitutes a national and global issue.

\section{CONCLUSIONS}

1. More than half of the researched group of patients were subjected to facial trauma under the influence of alcohol, 
with higher percentage of males compared to a low number of females.

2. Among the drunk patients, assault was the main cause of the trauma for the group aged 19-40, with mandibular fracture being the most common injury. At work, the majority of patients were sober.

3. The majority of road traffic accident casualties aged 19-40 and 41-60 were sober; none of the patients who incurred maxillofacial trauma while engaged in sport was under the influence of alcohol.

4. Drunk patients from urban areas significantly more frequently were subject to maxillofacial traumas as a result of assaults, whereas caused less by road traffic accidents, and did not work under the influence of alcohol which, however, occurred in $0.4 \%$ of farm labour cases.

5. Alcohol consumption was affected by gender, age, cause of trauma and place of residence in the analysis among maxillofacial trauma patients admitted to hospital within a one-year period.

\section{REFERENCES}

1.Wanyura H, Samolczyk-Wanyura D. Grupy klinicznoanatomopatologiczne złaman górnego masywu twarzy. Złamania odosobnione GMT.Czas Stomatol. 1992; 65(5): 287-293 (in Polish).

2. Kryst L. Chirurgia szczękowo-twarzowa. 5th ed. Warszawa, 2011; p. 247-263.

3. Voigt R. Hodgson. Tolerance of the facial bones to impact. American Journal of Anatomy.Volume 120, Issue 1, pages 113-122, January 1967.

4. Maciejewski R. red. Inżynieria biomedyczna Wybrane obszary zastosowań. Politechnika Lubelska. Lublin 2012. ISBN 978-83-6356904-4

5. Hampson D. J. Biomechanics 1995, vol. 28, No. 1, pp. 1-7.

6. Lee KF, Wagner LK, Lee YE, Suh JH, Lee SR. The impact-absorbing effects of facial fractures in closed-head injuries. An analysis of 210 patients. J Neurosurg. 1987 Apr; 66(4): 542-547.

7. O'Meara C, Witherspoon R, Hapangama N, Hyam DM. Alcohol and interpersonal violence may increase the severity of facial fracture. Br J Oral Maxillofac Surg. 2012 Jan; 50(1): 36-40.

8. Altura BM, Memon ZS, Altura BT, Cracco RQ. Alcohol-Associated Acute Head Trauma in Human Subjects Is Associated With Early Deficits in Serum Ionized Mg and Ca. Alcohol. 1995, Vol. 12, Issue $5,433-437$.
9. Adsett L, Thompson WM, Kieser JA, Tong DC. Patterns and trends in facial fractures in New Zealand between 1999 and 2009. New Zealand Dental Journal. Dec.2013, 142-147.

10. Shapiro AJ, Johnson RM, Miller SF, McCarthy MC. Facjal fractures in level I trauma centre: the importance of protective devices and alcohol abuse. Inj.Int.J Care Injured 32, 2001: 353-356.

11. Czapiński J, Panek T. Diagnoza społeczna 2011, warunki i jakość życia Polaków. Warszawa: Rada Monitoringu Społecznego. 30.09.2011 (in Polish).

12. Elledge RO, Elledge R, Aquilina P, Hodson J, Dover S. The role of alcohol in maxillofacial trauma: a comparative retrospective audit between the two centers. Alcohol. 2011 May;45(3): 239-243.

13. Laverick S, Patel N, Jones DC. Maxillofacial trauma and the role of alcohol. Br J Oral Maxillofac Surg. 2008; 46(7): 542-546.

14. Chen SC, Lin FY, Chang KJ. Body region prevalence of injury in alcoholand non-alcohol-related traffic injuries. J Trauma. 1999; 47(5): 881-884.

15. Bali RK, Sharma P, Garg A, Dhillon G. A comprehensive study on maxillofacial trauma conducted in Yamunanagar, India. J Inj Violence Res. 2013; 17 2003-2010.

16. Chandra Shekar BR, Reddy C. A five-year retrospective statistical analysis of maxillofacial injuries in patients admitted and treated at two hospitals of Mysore city. Indian J Dent Res. 2008; 19(4): 304-308.

17. Hutchison IL, Magennis P, Shepherd JP, Brown AE. The BAOMS United Kingdom survey of facial injuries part 1: aetiology and the association with alcohol consumption. British Association of Oral and Maxillofacial Surgeons. Br J Oral Maxillofac Surg. 1998; 36(1): 3-13.

18. Arslan ED, Solakoglu AG, Komut E, Kavaci C, Yilmaz F et al. Assessment of maxillofacial trauma in emergency department. Word J ofEmergency Surgery 2014: 9-13.

19. O’Meara C, Witherspoon R, Hapangama N, Hyam DM. Mandible fracture severity may be increased by alcohol and interpersonal violence. Aust Dent J. 2011; 56(2): 166-170.

20.Zix JA, Schaller B, Lieger O, Saulacic N, Thorén H, Iizuka T. Incidence, aetiology and pattern of mandibular fractures in central Switzerland. Swiss Med Wkly. 2011; 27, 141:w13207.

21. Lee KH, Snape L. Role of alcohol in maxillofacial fractures. N Z Med J. 2008; vol. 4, 121(1271): 15-23.

22. Lee K. Trend of alcohol involvement in maxillofacial trauma. Oral Surg Oral Med Oral Pathol Oral Radiol Endod. 2009;107(4): 9-13.

23. van Beek GJ, Merkx CA. Epidemiology of facial injuries. Ned Tijdschr Tandheelkd. 1997; 104(11): 414-417.

24. Oikarinen K, Silvennoinen U, Ignatius E. Frequency of alcoholassociated mandibular fractures in northern Finland in the 1980s. Alcohol Alcohol. 1992; 27(2): 189-193.

25. El-Maaytah M, Smith SF, Jerjes W, Upile T, Petrie A, Kalavrezos N, Ayliffe P, Newman L, Hopper C, Lloyd T. The effect of the new " 24 hour alcohol licensing law" on the incidence of facial trauma in London. $\mathrm{Br}$ J Oral Maxillofac Surg. 2008; 46(6): 460-463. 